\section{Medical Suspicion Overcomes Misleading Clinical and Labo- ratory Aspects of Genitourinary Tuberculosis}

\section{Florencia Neffa*, Analía Galvan, Sebastián Huelmo, Álvaro Despaux, Emmanuel Montana and Lucía García}

Department of Urology, Hospital de Clinicals, Montevideo, Uruguay

\begin{abstract}
Introduction: Tuberculosis is accountable for 2 billion people infected from Mycobacterium tuberculosis worldwide; ultimately 5 to $10 \%$ will get sick. Gold standard treatment is effective for the vast majority of the affected population. However, it remains an unresolved public health problem.

Case presentation: In this case report the authors portray the long journey of an immune competent, healthy, young patient towards genitourinary tuberculosis detection.

Conclusion: Tuberculosis is still to this day a concern of public health. Pulmonary as well as extra-pulmonary manifestations could develop in a misleading manner delaying best course of treatment. Specific and effective medication is available, which only evidences the fact that we are failing to diagnose properly and timely this deceiving disease.
\end{abstract}

Keywords: Genitourinary; Tuberculosis; Mycobacterium tuberculosis

\section{Key Note Message}

Fast and proper diagnosis of tuberculosis is of the essence to provide an optimal treatment and clinical care to the patient. Consideration of Genitourinary tuberculosis in patients from endemic areas who present with urinary symptoms, negative urine cultures,

*Corresponding author: Florencia Neffa, Department of Urology, Hospital de Clinicals, Montevideo, Uruguay, Tel: +598 99930860; Fax: +598 224873405; E-mail: floneffa@gmail.com

Citation: Neffa F, Galvan A, Huelmo S, Despaux A, Montana E, et al. (2019) Medical Suspicion Overcomes Misleading Clinical and Laboratory Aspects of Genitourinary Tuberculosis. J Clin Stud Med Case Rep 6: 075.

Received: August 22, 2019; Accepted: September 24, 2019; Published: October 01, 2019

Copyright: (C) 2019 Neffa F, et al. This is an open-access article distributed unde the terms of the Creative Commons Attribution License, which permits unrestricted use, distribution, and reproduction in any medium, provided the original author and source are credited. abnormal urinary tract imaging and in whom treatment for common urinary infections have failed, is clearly necessary. Even though medical therapy is currently available, delayed diagnosis could lead to chronic and/or fatal consequences.

\section{Introduction}

Tuberculosis (TB) is a major global cause of death, being a public health concern worldwide. Around one third of the world population is infected with Mycobacterium Tuberculosis (MBT), whereas these have a 5 to $15 \%$ lifetime risk of getting sick sick [1]. An alarming $95 \%$ is concentrated in developing countries [2]. According to 2012 ciphers, Asia concentrates up to $60 \%$ of all new cases per year [1]. Albeit specific standardized treatment is effective for most part of the affected population, it still remains an unresolved public health problem [3]. An estimated 1.3 million people died from TB in 2017. Out of the 10 million people who developed the illness $9 \%$ were HIV-positive. Immunological integrity status is key to successfully overcome the disease, being HIV carriers much more expose to disease and death [4]. Uruguay is denominated the Latin-American country with the lowest disease prevalence, detecting 2,76 deaths per 100.000 habitants in 2016 [5].

Extrapulmonary involvement can be expected in 10 to $42 \%$ of cases. The order of organ affection being: Pleural, lymph node, and renal TB (3 to 21\%) [6]. Urogenital TB (UGTB) is a much more silent ailment, mostly overlooked compared to pulmonary $\mathrm{TB}$, although being the second most common form of TB in countries with a severe epidemic situation and the third most common form in regions with a low incidence of TB.

The kidneys are primary targets due to hematogenous spread of the bacilli, mainly derived from prime pulmonary infection, with a 3 to 10-year dilatation, according to the host immune system integrity. Nonspecific clinical manifestations are the rule, often resulting in delayed diagnosis and ominous prognosis [7]. Sub diagnosis of UGTB arises many inconsistencies regarding different nomenclature, disease classification, therapeutic strategies and management.

The present publication describes a case of GUTB in a young, immuno-proficient man, with no personal or environmental history of $\mathrm{TB}$, with severe renal function loss and urinary tract obstruction symptoms, portraying the importance of acknowledging the misleading nature of clinical manifestations and naïve background.

\section{Materials and Methods}

The patient is a healthy 34-year-old male, with no personal or familial history of TB or HIV, nor previous contact with known TB individuals. He first presented at 31 years of age with symptomatic elevated blood pressure ciphers treated successfully with standard medication. Subsequent controls over a 3-year period of time showed a marked increase in creatinine levels. Recent episodes of persistent fever and dysuria in an acute renal failure context, triggered a full 
Citation: Neffa F, Galvan A, Huelmo S, Despaux A, Montana E, et al. (2019) Medical Suspicion Overcomes Misleading Clinical and Laboratory Aspects of Genitourinary Tuberculosis. J Clin Stud Med Case Rep 6: 075.

medical, urological and nephrological evaluation. Clinical examination was consistent with: Lumbar bilateral pain, enlarged prostate in rectal palpation and multiple urethral strictures. Computed tomography of chest-abdomen and pelvis without contrast was done. Figure 1 laboratory tests showed the following results: hemoglobin $8,4 \mathrm{mg} /$ $\mathrm{dL}$; white blood count 12,690 mg/mm3; creatinine $6.08 \mathrm{mg} / \mathrm{dL}$ (estimated glomerular filtration rate $(\mathrm{GFR})=18,16 \mathrm{~mL} / \mathrm{min}$ based on Cockroft-Gault formula); urea $133 \mathrm{mg} / \mathrm{dL}$; the patient tested negative for hepatitis B, hepatitis C, Human Immune Deficiency Virus (HIV) infection and syphilis. Urinalysis showed the following results: $\mathrm{pH}$ 5.5 , leukocyturia 50/high power field and hematuria 15 /high power field. One hemo culture and three consecutive urine cultures were performed not yielding any positive findings. Urine and pulmonary bacilloscopys were negative for Mycoplasma TB (Figure 1).
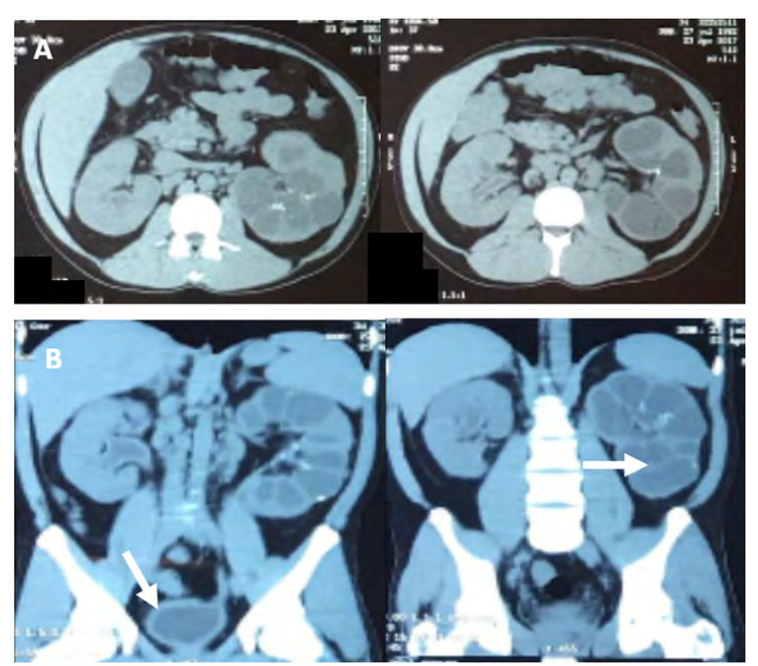

Figure 1: A) Sagittal view of abdominal computer tomography. B) Coronal view of abdómino-pelvis computer tomography.

Arrows pointing at pyelocaliceal dilation of RK; severe hydronefrosis of LK; and thick bladder walls.

Patient manifested rapid clinical deterioration with increasing creatinine and azotemia ciphers and infection parameters, combined with high fever, pyuria and right flank pain. An anesthetized exploratory urethro-cystoscopy was performed, observing an indurated urethra with diminished caliber, a poor capacity bladder with inflammatory aspect and a whitish substance covering almost all vesical surface. Sample biopsy from bladder wall and pyuric urine from left urether were taken for analytic purposes. Urine derivation was performed by placing a uretheral and vesical catheter. The pathology report informed a granulomatous necrotic process of the bladder with a negative Ziehl Nielsen test result. The urine bacilloscopy was finally positive for Mycobacterium TB. A posterior urine culture using the Lowenstein-Jensen medium isolated M. tuberculosis.

Based on these results, the patient began a 6-month course of rifampin, isoniazid, pyrazinamide and ethambutol according to World Health Organization current guidelines. According to the classification of UGTB8 some of the complications already observed were: unilateral kidney loss, right polycavernous kidney, hydronefrosis, shruncken bladder, renal failure, urethral stricture and clinical prostate TB. Patient is now in a pre-hemodialysis list, with a GFR of 28 $\mathrm{ml} / \mathrm{seg}$ despite adequate treatment.

\section{Discussion}

As stated by the World Health Organization (WHO) in 2014, over $30 \%$ of the worldwide population are infected by Mycobacterium tuberculosis, and these carry an accumulated risk of $10 \%$ of suffering from Tuberculosis throughout their lifetime [8]. This disease is the second most frequent cause of death due to a single infectious microorganism8. Most of the focus is put into pulmonary TB, however, GUTB is a frequent manifestation of Mycobacterium tuberculosis infection and due to misleading symptoms causing late diagnosis, the prognosis is often compromise, in spite of having an adequate course of treatment.

Regarding GUTB, there are no specific clinical signs a practitioner could rely to diagnose it. When considering this pathology, it includes a wide spectrum of symptoms among different patients, but most importantly between the various forms and stages of the disease, making it impossible to apply a standard unified approach of diagnosis and treatment [8]. In patients from endemic areas who present with: urinary symptoms, negative urine cultures, abnormal urinary tract imaging and in whom treatment for common urinary infections have failed, a high degree of clinical suspicion is clearly necessary. Delayed diagnosis is detrimental, leading to chronic and fatal consequences [9].

\section{Conclusion}

Tuberculosis is an ancient disease which still remains in a latent form in a great part of the world's development countries population, affecting the most vulnerable individuals, generating millions of deaths. Both pulmonary and extra-pulmonary manifestations could develop in a misleading manner, causing late diagnosis and delaying best course of treatment. Specific and effective medication is available, which only adds concern to the fact that we are failing in recognizing properly and timely this deceiving disease. We portrayed the story of one immune proficient, healthy, young patient through his 3-year journey towards GUTB detection.

\section{References}

1. WHO (2018) Tuberculosis. WHO, Geneva, Switzerland.

2. Kulchavenya E (2013) Best practice in the diagnosis and management of urogenital tuberculosis. Ther Adv Urol 5: 143-151.

3. Barry C, Konstantinos A; National Tuberculosis Advisory Committee (2009) Tuberculosis notifications in Australia, 2007. Commun Dis Intell Q Rep 33: 304-315.

4. World Health Organization (2014) Global Tuberculosis report 2014. World Health Organization, Geneva, Switzerland.

5. Pan American Health Organization (2016) Situation of tuberculosis in Uruguay. Pan American Health Organization, Uruguay.

6. Gibson MS, Puckett ML, Shelly ME (2004) Renal tuberculosis. Radiographics 24: 251-256.

7. Abbara A, Davidson RN (2011) Etiology and management of genitourinary tuberculosis. Nat Rev Urol. 8: 678-688.

8. Kulchavenya E (2014) Urogenital tuberculosis: Definition and classification. Ther Adv Infect Dis 2: 117-122.

9. Zarrabi AD, Heyns CF (2009) Clinical Features of Confirmed Versus Suspected Urogenital Tuberculosis in Region With Extremely High Prevalence of Pulmonary Tuberculosis. Urology 74: 41- 45 


\section{II}

Journal of Anesthesia \& Clinical Care

Journal of Addiction \& Addictive Disorders

Advances in Microbiology Research

Advances in Industrial Biotechnology

Journal of Agronomy \& Agricultural Science

Journal of AIDS Clinical Research \& STDs

Journal of Alcoholism, Drug Abuse \& Substance Dependence

Journal of Allergy Disorders \& Therapy

Journal of Alternative, Complementary \& Integrative Medicine

Journal of Alzheimer's \& Neurodegenerative Diseases

Journal of Angiology \& Vascular Surgery

Journal of Animal Research \& Veterinary Science

Archives of Zoological Studies

Archives of Urology

Journal of Atmospheric \& Earth-Sciences

Journal of Aquaculture \& Fisheries

Journal of Biotech Research \& Biochemistry

Journal of Brain \& Neuroscience Research

Journal of Cancer Biology \& Treatment

Journal of Cardiology: Study \& Research

Journal of Cell Biology \& Cell Metabolism

Journal of Clinical Dermatology \& Therapy

Journal of Clinical Immunology \& Immunotherapy

Journal of Clinical Studies \& Medical Case Reports

Journal of Community Medicine \& Public Health Care

Current Trends: Medical \& Biological Engineering

Journal of Cytology \& Tissue Biology

Journal of Dentistry: Oral Health \& Cosmesis

Journal of Diabetes \& Metabolic Disorders

Journal of Dairy Research \& Technology

Journal of Emergency Medicine Trauma \& Surgical Care

Journal of Environmental Science: Current Research

Journal of Food Science \& Nutrition

Journal of Forensic, Legal \& Investigative Sciences

Journal of Gastroenterology \& Hepatology Research

Journal of Gerontology \& Geriatric Medicine
Journal of Genetics \& Genomic Sciences

Journal of Hematology, Blood Transfusion \& Disorders

Journal of Human Endocrinology

Journal of Hospice \& Palliative Medical Care

Journal of Internal Medicine \& Primary Healthcare

Journal of Infectious \& Non Infectious Diseases

Journal of Light \& Laser: Current Trends

Journal of Modern Chemical Sciences

Journal of Medicine: Study \& Research

Journal of Nanotechnology: Nanomedicine \& Nanobiotechnology

Journal of Neonatology \& Clinical Pediatrics

Journal of Nephrology \& Renal Therapy

Journal of Non Invasive Vascular Investigation

Journal of Nuclear Medicine, Radiology \& Radiation Therapy

Journal of Obesity \& Weight Loss

Journal of Orthopedic Research \& Physiotherapy

Journal of Otolaryngology, Head \& Neck Surgery

Journal of Protein Research \& Bioinformatics

Journal of Pathology Clinical \& Medical Research

Journal of Pharmacology, Pharmaceutics \& Pharmacovigilance

Journal of Physical Medicine, Rehabilitation \& Disabilities

Journal of Plant Science: Current Research

Journal of Psychiatry, Depression \& Anxiety

Journal of Pulmonary Medicine \& Respiratory Research

Journal of Practical \& Professional Nursing

Journal of Reproductive Medicine, Gynaecology \& Obstetrics

Journal of Stem Cells Research, Development \& Therapy

Journal of Surgery: Current Trends \& Innovations

Journal of Toxicology: Current Research

Journal of Translational Science and Research

Trends in Anatomy \& Physiology

Journal of Vaccines Research \& Vaccination

Journal of Virology \& Antivirals

Archives of Surgery and Surgical Education

Sports Medicine and Injury Care Journal

International Journal of Case Reports and Therapeutic Studies

Journal of Ecology Research and Conservation Biology

Submit Your Manuscript: http://www.heraldopenaccess.us/Online-Submission.php 